\title{
In-situ observations of dendritic fragmentation during directional solidification of Sn-10wt.\% Bi alloy
}

\author{
*Ji-hui Luo \\ College of Materials Science and Engineering, Yangtze Normal University, Chongqing 408100, China
}

\begin{abstract}
The stray crystals seriously affect the properties of metals which fabricated by directional solidification (DS). In order to observe the formation of the stray crystals, the growth behavior of Sn-10wt.\%Bi alloy was observed by synchrotron X-ray imaging technique using self-developed directional solidification (DS) apparatus. The experimental results show that $\mathrm{Sn}-10 \mathrm{wt}$.\%Bi alloy is oriented with the form of dendrites to grow into the liquid phase during the DS process, and dendrites are arranged neatly to form columnar crystal microstructures. It is also found that parts of the dendrite arms begin to crack. These cracked dendrites drift upward to grow up in front of the solid-liquid interface and form stray crystals.
\end{abstract}

Key words: Sn-Bi alloy; synchrotron X-ray radiography; directional solidification; dendritic fragmentation

CLC numbers: TG146.1 ${ }^{+} \quad$ Document code: A

Article ID: 1672-6421/2019)04-262-05

$\mathrm{C}$ olumnar crystals, which have high ductility and conductivity, can be obtained during heated mold continuous casting (HMCC) ${ }^{[1-3]}$. However, an improper mold temperature during HMCC can lead to some stray crystals in the columnar crystals. It is believed that wall nucleation occurs when the mold temperature is lower than the liquidus of the alloy ${ }^{[4,5]}$, or because of heterogeneous nucleation due to dendritic fusing ${ }^{[6,7]}$. Since the microstructure is difficult to observe during the solidification process, directly describing the formation of the stray crystals is infeasible. For a long time, the researchers mainly observed the solidification of transparent organic solution to simulate the metal solidification process ${ }^{[8-10]}$. The advantage of this method is that the solidification process can be directly visualized by using microscopic observation. For instance, Witusieuics et al. ${ }^{[11]}$ observed the solidification of succinonitrile-camphor solution by directional solidification. Such observations are useful for understanding the solidification of metallic materials. However, this method cannot reflect the real solidification behavior of solid metal due to the

\footnotetext{
*Ji-hui Luo
}

Male, born in 1978, Ph. D., Prof. Research interests: non-ferrous metal processing.

Received: 2019-01-14; Accepted: 2019-04-23 difference between the organic solution and the actual metal material.

With the development of X-ray technology, synchrotron radiation technology began to play an important role in the field of materials solidification ${ }^{[12-16]}$. Synchrotron radiation technology has the advantages of high energy, brightness, resolution and good monochromaticity, and it can meet the requirements of real-time imaging of microstructure changes during the transformation of solid phase to liquid phase. In recent years, many studies have been carried out on the growth behavior of dendrites during the solidification process of metal with the synchrotron radiation source. For example, Ruvalcaba et al. ${ }^{[17]}$ studied Al-20wt. $\% \mathrm{Cu}$ alloy by using a Bridgman furnace, and the process of dendrite crack was recorded by European Synchrotron Radiation Facility. Reinhart et al. ${ }^{[18]}$ also investigated Al-3.5wt.\%Ni alloy using a Bridgman furnace and the same results were obtained.

Compared with traditional absorption contrast imaging, diffraction enhancement imaging can clearly obtain the internal structure of the sample based on phase contrast. In this work, a Sn-10wt.\%Bi alloy with a low melting point was used as the experimental material. A directional solidification furnace with the controlled mold temperature was designed to carry out the directional solidification (DS) process for the Sn-10wt.\%Bi alloy. During the DS process, real-time 
imaging of microstructure changes can be obtained by the synchrotron radiation X-ray device of Institute of High Energy Physics, Chinese Academy of Sciences. The imaging results of the $\mathrm{Sn}-10 \mathrm{wt} . \% \mathrm{Bi}$ alloy were then analyzed and discussed.

\section{Experimental}

\subsection{Experimental material and equipment}

In this work, Sn-10wt.\%Bi alloy samples were prepared with 99.9wt.\%Sn and 99.9wt.\%Bi. Firstly, the Sn and Bi were charged into a vacuum melting furnace to melt at $300{ }^{\circ} \mathrm{C}$ for $20 \mathrm{~min}$. Then the melt was poured into a graphite mold. After natural cooling, the Sn-10wt.\%Bi alloy was rolled into film with a size of $80 \times 12 \times 0.1 \mathrm{~mm}^{3}$.

A directional solidification furnace was designed with a window for the X-ray to pass through the sample. The furnace includes heating and cooling devices. The heating device was used to melt the alloy sample and to control the ceramic mold temperature. The mold can be moved along the vertical direction between the heating and cooling devices. Figure 1 shows a sketch of the experimental method. Experimental apparatus consists of heating device, temperature controller, ceramic mold and cooling device. The Sn-10wt.\%Bi alloy film can be put in the ceramic mold and heated to the required temperature by the heating device. Meanwhile, the ceramic mold at the lower end was forced to cool. A charge-coupled device (CCD) camera was set to take the images.

\subsection{Experimental procedure}

The experiment was carried on beamline 4W1A of Beijing Synchrotron Facility (BSRF), China. The distance of CCD to the sample is $15-30 \mathrm{~cm}$ and the view size of the CCD is $4 \times 6 \mathrm{~mm}^{2}$. The exposure time is $600-900 \mathrm{~ms}$ and the X-ray energy is 20$21 \mathrm{keV}$.

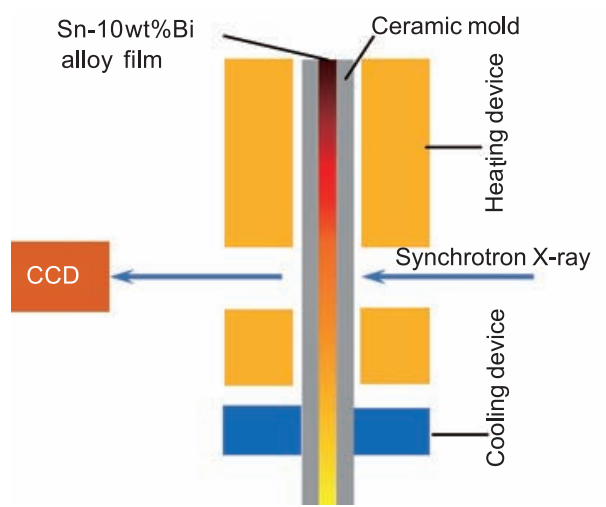

Fig. 1: Sketch of experimental method

The experiment process is as follows: put the $\mathrm{Sn}-10 \mathrm{wt} . \% \mathrm{Bi}$ alloy foil into the ceramic mold and adjust the position of the thermocouple. The X-ray can smoothly pass through the observation window after adjusting the height of the directional solidification furnace. While the sample was observed in the monitoring and control system, the ceramic mold was heated to a temperature of $300{ }^{\circ} \mathrm{C}$ by the heating device, then the sample in the ceramic mold was melted into liquid metal. After heat preservation for 5 minutes, the ceramic mold temperature was gradually decreased according to the rate of $10{ }^{\circ} \mathrm{C} \cdot \mathrm{min}^{-1}$, and continued to decrease the temperature to $210{ }^{\circ} \mathrm{C}$. Thereafter, the ceramic mold temperature was decreased at a rate of $1-3{ }^{\circ} \mathrm{C} \cdot \mathrm{min}^{-1}$. The imaging changes of the sample were recorded by $\mathrm{CCD}$ during the cooling process.

\section{Results and discussion}

A good phase-contrast can be formed due to the X-ray absorption capacity of solid and liquid where an obvious difference exists. Therefore, CCD camera can capture a clear X-ray image. Figure 2 is the radiography sequence showing the evolution of Sn-10wt.\%Bi alloy, in which the ceramic mold temperature is controlled at $188^{\circ} \mathrm{C}$. It can be seen from Fig. 2(a), at the bottom of the field, the white dendrites grow up, and the secondary dendrites grow on the primary dendrites. The average diameter of the primary dendrite is $\sim 60 \mu \mathrm{m}$, and the average distance between the primary dendrites is $\sim 275 \mu \mathrm{m}$. It also can be seen that the growth direction of the primary dendrites is significantly different. Some primary dendritic clusters with the same growth direction will compose a columnar crystal. It is concluded that there are five columnar crystals in the field of view, and there is a wide gap between the two crystals. In this experiment, at the top of the ceramic mold, the temperature is controlled at $188^{\circ} \mathrm{C}$. At the bottom of ceramic mold, the cooling water was forced to cool the ceramic mold and the alloy, so there exists a top-down temperature gradient in the ceramic mold. On the other hand, because the temperature of the ceramic mold is controlled in the two-phase zone of the alloy, there also exists a horizontal heat transfer direction. Therefore, the growth direction of the primary dendrites is not completely vertical and has a certain angle of $\sim 60^{\circ}$ with the vertical direction.

Figure 2(b) shows the imaging results at the time of $t_{0}+12 \mathrm{~s}\left(t_{0}\right.$ represents the start time of the sequences). It can be found that a cracked dendrite appears (in the white circle). Compared with the dendrite morphology in the white circle of Fig. 2(a), it can be seen that the fragment, caused by secondary dendrite fusing, is detached from the primary dendrite. The secondary dendrite fusing may be due to Bi solute enriching in front of solid-liquid interface, leading to $\mathrm{Bi}$ content enriching between the primary diameter and the root of the secondary dendrites. As the solute increases, the melting point of the alloy in the local range begins to decrease. The roots of the secondary dendrites are fused to form a fracture. Another theory is that there exists convection in front of the liquid phase of liquid-liquid interface. Under the action of external force, secondary dendrites were cut by the flow of the liquid phase, resulting in fragments of secondary dendrite from primary ones ${ }^{[19]}$.

Figure 2(c) is the imaging result at $t_{0}+16 \mathrm{~s}$. It can be seen that the detached dendrite, which in the white circle, began to drift to the left, and the drift distance is $\sim 5 \mu \mathrm{m}$. Meanwhile, the detached dendrite grows up, as shown in Fig. 2(d). At the same 

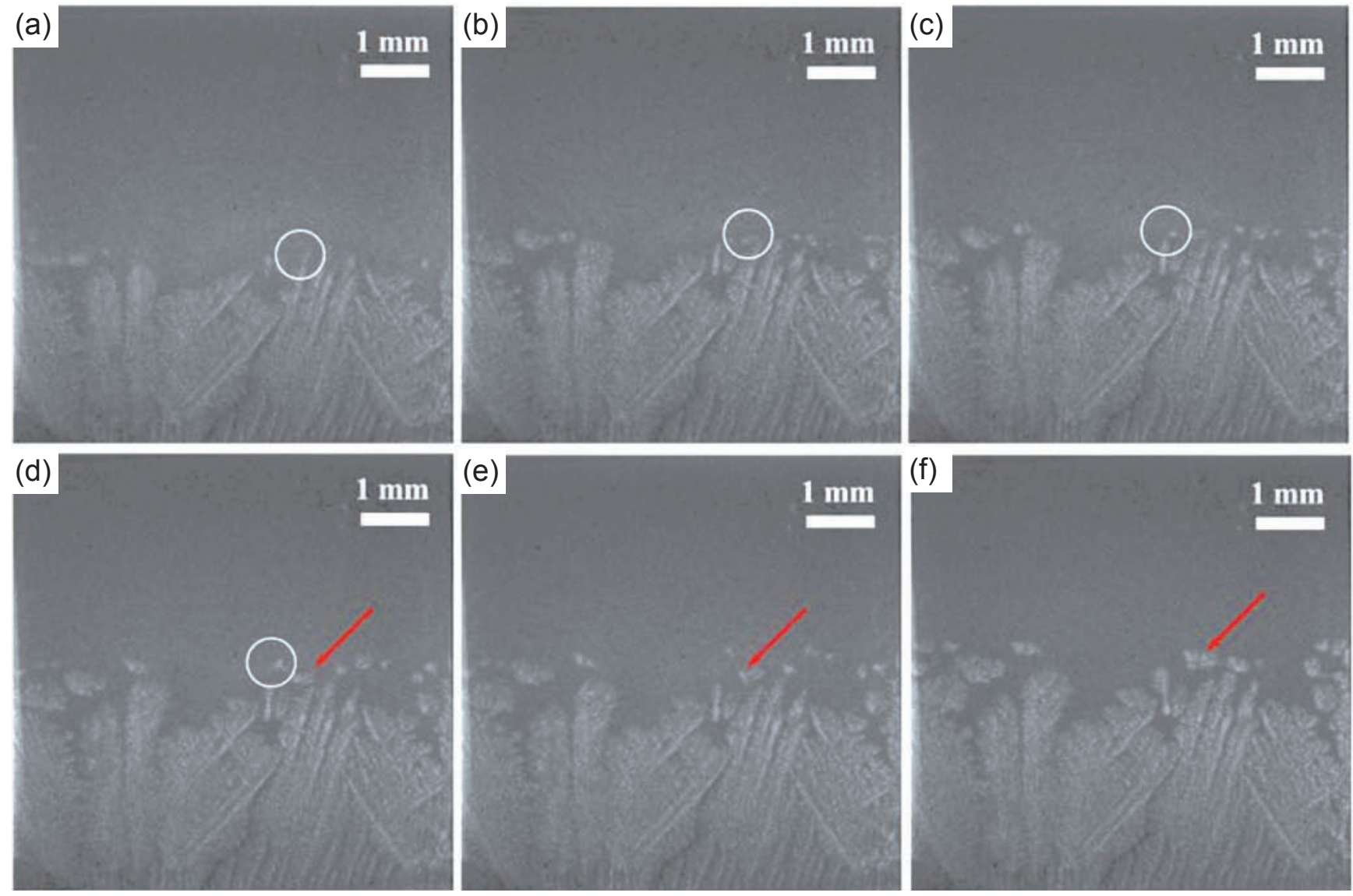

Fig. 2: Sequences of growth behavior of Sn-10wt.\%Bi alloy $\left(188^{\circ} \mathrm{C}\right)$ : (a) $t_{0} \mathrm{~s}$; (b) $t_{0}+12 \mathrm{~s}$; (c) $t_{0}+16 \mathrm{~s}$; (d) $t_{0}+18 \mathrm{~s}$; (e) $t_{0}+22 \mathrm{~s}$; (f) $t_{0}+26 \mathrm{~s}$

time, on the right side, another detached dendrite, indicated by the red arrow, begins to move upwards and far away from the primary dendrite. With the time increasing, the volume of detached dendrite (in the white circle) becomes smaller and even begins to disappear, as shown in Fig. 2(e). However, another volume of detached dendrite, indicated by the red arrow, begins to increase. Figure 2(f) is the imaging result at $t_{0}+26 \mathrm{~s}$. It can be seen that the dendrite in the white circles of Figs. 2(a)(e) has completely disappeared. The reason may be the detached dendrite dissolves at the high temperature region. The dendrite, indicated by the red arrow, begins to grow up and the volume gradually increased.

When the mold temperature decreases to $185^{\circ} \mathrm{C}$, morphological changes of phase are shown in Fig. 3. Figure 3(a) shows there is a detached dendrite in the white circle. The detached dendrite drifts upwards and grows up, as shown in Fig. 3(b). The fragment begins to become thicker in the liquid phase. Figure 3(c) is the imaging result at $t_{0}+54 \mathrm{~s}$. It can be seen that the position of the dendrite is further moved upwards. At the same horizontal line, the position of the dendrite is significantly higher than that of Figs. 3(a) and (b). At the same time, it also can be found that the volume of all detached dendrites begins to increase gradually. From the above results, while the mold temperature decreases, the detached dendrite will grow up during floating and there is no dissolution.

With decreasing the mold temperature, the detached dendrites can grow larger. Figure 4 shows the morphological changes when the mold temperature decreases to $182{ }^{\circ} \mathrm{C}$. Those detached dendrites will form equiaxed crystals in front of the columnar crystals. For example, an equiaxed crystal, indicated by the red arrow in Fig. 4(a), is developed from the detached dendrite in the white circle of Fig. 3. These crystals hinder the further growth of columnar crystals, leading to a microstructure of coexistence of columnar crystals and equiaxed crystals, as shown in Fig. 4(b).

The above results show that under the great temperature gradient, columnar crystal microstructures will be formed during the directional solidification Sn-10wt.\%Bi alloy process. The columnar crystals grow in a dendritic manner. The cracks of primary dendrites and secondary dendrites occur. These cracked dendrites will float up into the liquid phase, and some of the detached dendrites begin to melt and disappear during the floating. The other detached dendrites will grow up to form new equiaxed crystals. The growth of these equiaxed crystals in front of solid-liquid interface hinders the further growth of columnar crystals, and the formation of equiaxed crystals destroyed the integrity of columnar crystal growth. 

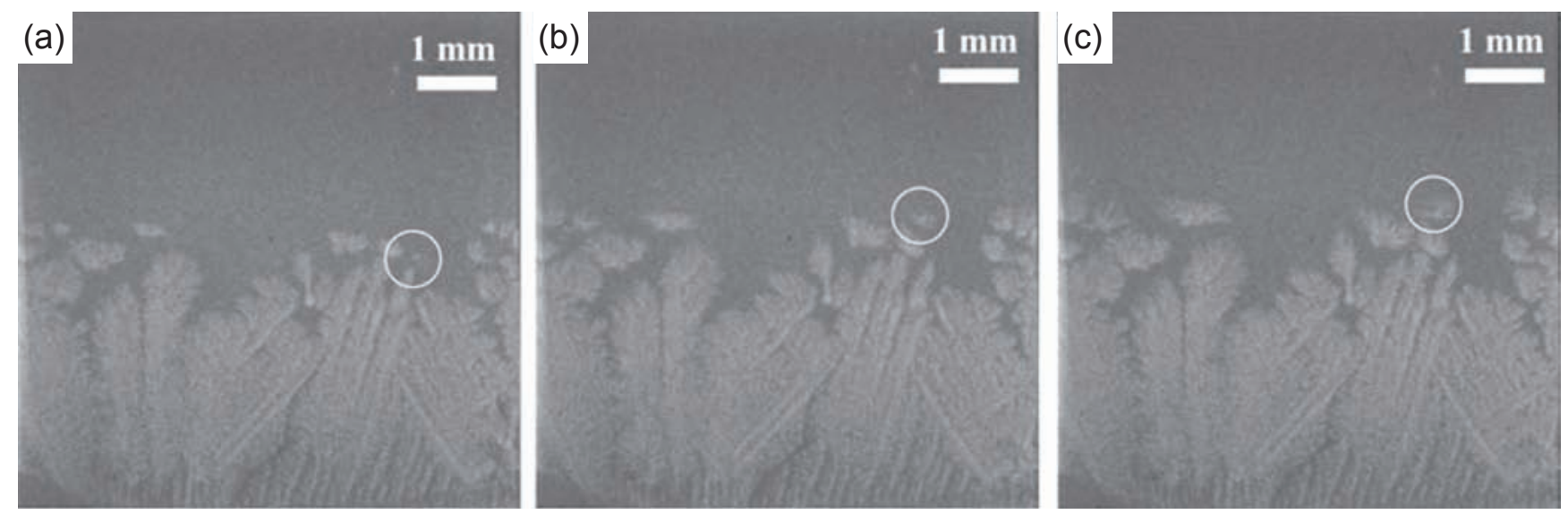

Fig. 3: Sequences of growth behavior of Sn-10wt. $\%$ Bi alloy $\left(185^{\circ} \mathrm{C}\right)$ : (a) $t_{0}+30 \mathrm{~s}$; (b) $t_{0}+46 \mathrm{~s}$; (c) $t_{0}+54 \mathrm{~s}$
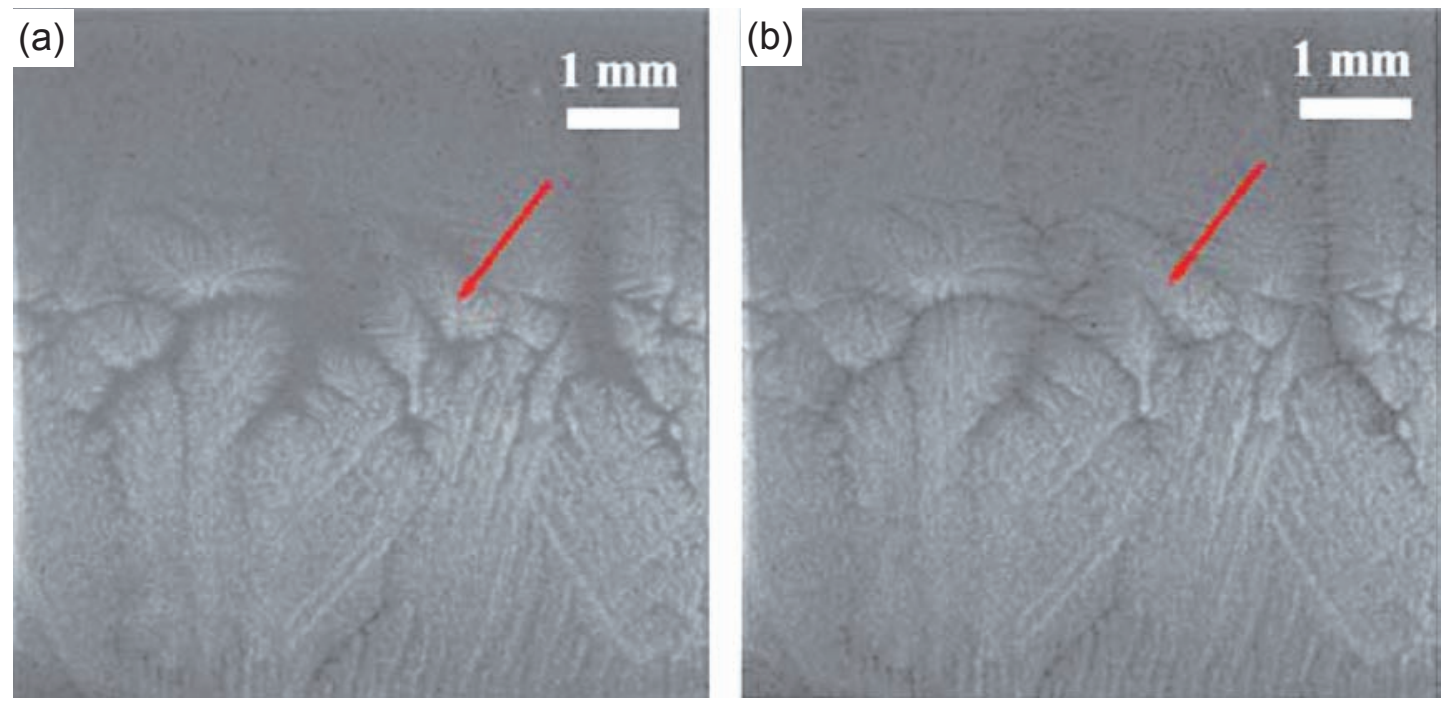

Fig. 4: Sequences of growth behavior of Sn-10wt. $\%$ Bi alloy $\left(182^{\circ} \mathrm{C}\right)$ : (a) $t_{0}+108 \mathrm{~s}$; (b) $t_{0}+148 \mathrm{~s}$

\section{Conclusions}

Synchrotron radiation was used in a self-designed directional solidification furnace to achieve the imaging observation of growth behavior of Sn-10wt.\%Bi alloy. While the mold temperature was controlled between the solidus and liquidus of the alloy at $188^{\circ} \mathrm{C}$, it is possible to observe simultaneously the upward growth of dendrites, which form the columnar crystals. It is also found that parts of the dendrite arms begin to crack. While the mold temperature was decreased to $182{ }^{\circ} \mathrm{C}$, these cracked dendrites drift upward to grow up in front of the solidliquid interface and form stray crystals.

\section{References}

[1] Ohno A. Continuous casting of singles crystal ingots by the O.C.C process. Journal of Metals, 1986, 38(1): 14-16.

[2] Wang Yu, Huang Haiyou, Xie Jianxin. Enhanced roomtemperature tensile ductility of columnar-grained polycrystalline $\mathrm{Cu}-12 \mathrm{wt}$ \% $\mathrm{Al}$ alloy through texture control by Ohno continuous casting process. Materials Letters, 2011, 65(7): 1123-1126.

[3] Wang $Y H$, Xiao L R, Zhao X J, et al. Microstructure and mechanical properties of columnar-grained copper produced by the Ohno continuous casting technique. Materials Science and Engineering A, 2015, 639: 122-130.

[4] Turnbull D. Formation of crystal nuclei in liquid metals. Journal of Applied Physics, 1950. 21(10): 1022-1028.

[5] Turnbull D. Kinetics of solidification of supercooled liquid mercury droplets. The Journal of Chemical Physics, 1952. 20(3): 411-424.

[6] Yamazaki M, Natsume $\mathrm{Y}$, Harada $\mathrm{H}$, et al. Numerical simulation of solidification structure formation during continuous casting in $\mathrm{Fe}-0.7 \mathrm{mass} \% \mathrm{C}$ alloy using cellular automaton method. ISIJ International, 2006, 46: 903-908.

[7] Li Chong, Liu Xiangfa, Wu Yuying. Refinement and modification performance of Al-P master alloy on primary $\mathrm{Mg} 2 \mathrm{Si}$ in $\mathrm{Al}-\mathrm{Mg}-$ Si alloys. Journal of Alloys and Compounds, 2008, 465(1-2): 145-150.

[8] Kant S, Rai R N. Solid-liquid equilibrium and thermochemical studies of organic analogue of metal-nonmetal system: Succinonitrile-pentachloronitrobenzene. Thermochimica Acta, 2011, 512(1): 49-54.

[9] Ocak Y, Akbulut S, Böyük U. et al. Solid-liquid interfacial 
energy for solid succinonitrile in equilibrium with succinonitrile dichlorobenzene eutectic liquid, Thermochimica Acta, 2006, 445(1): 86-91.

[10] Farup I, Drezet J M, Rappaz M. In situ observation of hot tearing formation in succinonitrile-acetone. Acta Materialia, 2001, 49(7): 1261-1269.

[11] Witusiewicz V T, Sturz L, Hecht U, et al. Thermodynamic description and unidirectional solidification of eutectic organic alloys: I. Succinonitrile-(D)camphor system. Acta Materialia, 2004, 52: 4561-4571.

[12] Mathiesen R H, Arnberg L. X-ray radiography observations of columnar dendritic growth and constitutional undercooling in an Al-30wt\%Cu alloy. Acta Materialia, 2005, 53: 947-956.

[13] Etgens V H, Martins Alves M C, Tadjeddine A. In situ surface $X$-ray diffraction studies of electrochemical interfaces at a highenergy third-generation synchrotron facility. Electrochimica Acta, 1999, 45(4-5): 591-599.

[14] Wang Tongmin, Cao Fei, Zhou Peng, et al. Study on diffusion behavior and microstructural evolution of $\mathrm{Al} / \mathrm{Cu}$ bimetal interface by synchrotron $\mathrm{X}$-ray radiography. Journal of Alloys and Compounds, 2014, 616: 550-555.
[15] Zhu Jing, Wang Tongmin, Cao Fei, et al. Real time observation of equiaxed growth of $\mathrm{Sn}-\mathrm{Pb}$ alloy under an applied direct current by synchrotron microradiography. Materials Letters, 2012, 89:137-139.

[16] Liao Hengcheng, Zhao Lei, Wu Yunna, et al. Investigation on Formation Mechanism of Irregular Shape Porosity in Hypoeutectic Aluminum Alloy by X-Ray Real Time Observation. Metallurgical and Materials Transactions A, 2012, 43(8):25872590.

[17] Ruvalcaba D, Mathiesen R H, Eskin D G, et al., Katgerman $\mathrm{L}$. In situ observations of dendritic fragmentation due to local solute-enrichment during directional solidification of an aluminum alloy. Acta Materialia, 2007, 55: 4287-4292.

[18] Reinhart G, Mangelinck-Noël N, Nguyen-Thi H, et al. Investigation of columnar-equiaxed transition and equiaxed growth of aluminium based alloys by X-ray radiography. Materials Science and Engineering A, 2005, 413-414: 384-388.

[19] Liotti E, Lui A, Kumar S, et al. The spatial and temporal distribution of dendrite fragmentation in solidifying Al-Cu alloys under different conditions. Acta Materialia, 2016, 121: 384395. 